\title{
Occurrence of triphenylphosphine oxide and other organophosphorus compounds in indoor air and settled dust of an institute building
}

\author{
Yasir Faiz ${ }^{1,2}$, Wei Zhao ${ }^{1}$, Jianfang Feng ${ }^{1}$, Cheng Sun ${ }^{1 *}$, Huan $\mathrm{He}^{1}$, Jiping Zhu ${ }^{3 \#}$ \\ ${ }^{1}$ State Key Laboratory of Pollution Control and Resource Reuse, School of the Environment, Nanjing University, \\ Nanjing 210023, PR China \\ ${ }^{2}$ Chemistry Division, PINSTECH, P.O. Nilore, Islamabad, Pakistan \\ ${ }^{3}$ Exposure and Biomonitoring Division, Health Canada, Ottawa, Ontario, Canada
}

${ }^{*}$ Corresponding author. Tel.: +86 25 89680258, e-mail: envidean@ @ju.edu.cn (C. Sun)

\# Co-corresponding author: Tel: +1 613946 0305, email: jiping.zhu@canada.ca (J. Zhu) 


\begin{abstract}
Indoor environments contain a wide range of synthetic products that emit a variety of semivolatile organic compounds (SVOCs). Among these SVOCs, organophosphorus compounds (OPs) are ubiquitous in indoor environments with relatively high concentrations. This study investigated the occurrence of seven OPs including triphenylphosphine oxide (TPPO) in three different types of indoor spaces (offices, conference halls and laboratories) of an institute building. A total of 39 airborne particulate matter $\left(\mathrm{PM}_{10}\right)$ and ten settled dust samples were analyzed. Among the seven target OPs, tri(2-chloroethyl) phosphate (TCEP), tri(chloropropyl) phosphate (TCPP) and TPPO were the major ones found in these samples. TPPO was for the first time identified in indoor environments with levels up to $94 \mathrm{ng} / \mathrm{m}^{3}$ in indoor air and 1.1 $\mu \mathrm{g} / \mathrm{g}$ in the indoor settled dust. Positive identity of TPPO in the samples was confirmed by comparisons of the mass spectrum of TPPO peak with that of TPPO standard and same GC retention time of TPPO from samples and from the standard. Compositions of OPs in these samples revealed different sources of OPs present in the indoor spaces. An equilibrium model was used to predict OPs in settled indoor dust from their corresponding levels found in indoor airborne particulate matters. There was a statistically significant correlation between predicted and measured OPs in settled dust in all three types of indoor spaces. The difference between measured and model predicted OP levels in settled dust was in the general range of predictions reported for indoor air SVOCs.
\end{abstract}

Key words: Organophosphorus compounds; Triphenylphosphine oxide; Flame retardants; Indoor dust; Particulate matter; Equilibrium model 


\section{Introduction}

Organophosphorus compounds (OPs) are one type of semi-volatile organic compounds (SVOCs) and are widely used in many consumer products. Chlorinated OPs such as tri(2chloroethyl) phosphate (TCEP), tri(chloropropyl) phosphate (TCPP) and tri(dichloropropyl) phosphate (TDCP) are added as flame retardants to many products such as flexible and rigid PUFs, while non-halogenated OPs are mainly used in products serving as plasticizers [1]. OPs are also used as anti-foaming, stabilizers and wetting agents in products such as floor polishes, hydraulic liquids, paints and lubricants [1,2]. Global data showed that OPs account for $16 \%$ of flame retardants used worldwide in 2013 [3]. In the last two decade, global consumption of OPs has risen steadily, from 102 kilo-tons in 1991 to 320 kilo- tons in 2013, of which China consumed a quarter of the chemicals [3-5]. Concerns about human exposure to OPs are due to the fact that some OPs have shown various toxicities to biota including humans [6]. A brief summary of published data on health effects of OPs has been provided in the supporting information (Table S1).

OPs have been found in higher abundance indoors than outdoors due to use of indoor products that contain OPs $[1,7,8]$. Recent two review articles on the occurrence of OPs have demonstrated the ubiquitous presence of OPs in the environment including various indoor environments $[1,2]$. However, information on the prevalence of OPs in university campuses is still scarce. Furthermore, triphenylphosphine oxide (TPPO), a compound whose structure is quite different from organophosphate, has been reported to be present in aquatic systems including wastewater effluent [9] and rivers [10]. TPPO is extensively employed as an 
intermediate in chemical reactions for pharmaceutical products and as a ligand for many transitional metals and therefore industrial production may be a source for TPPO in waters [11]. TPPO was also considered as possible substitute for bromine-containing formulations used in textile back-coatings [2]. There was also indication that TPPO is used as epoxy cure catalyst in polyurethane foam (PUF) [12]. If TPPO is used as flame retardants in indoor products [13], it may result in its presence indoors. However, TPPO presence in indoor environment has not been investigated and reported.

Depending on the physical properties, SVOCs can partition in both gas and solid phases [14]. OPs, due to their large octanol-air partition coefficient $\left(\mathrm{K}_{\mathrm{oa}}\right)$ values (Table 1$)$, are thought to be present mainly in particle phase in air. Particle-bound chemicals are critical in the assessment of human health risks because they might result in highly localized concentrations in the respiratory tracks at the site of particle deposition $[15,16]$. Furthermore, airborne particles are significant carriers of particle-bound chemicals from their original source to other indoor locations through air advection, deposition and re-suspension [17].

Several mathematical models have been reported to understand SVOCs dynamics [1822]. However, emissions of SVOCs are inherently more complicated to predict than those of VOCs [23]. Quite a few experimental studies were conducted based on dynamic measurements. Dynamics of airborne particles can strongly influence the transportation of chemicals that are bound to particles [24-27]. Under typical indoor conditions, kinetic constraints could influence the partitioning of SVOCs, particularly for those having a high octanol-air partition coefficient $\left(\mathrm{K}_{\mathrm{oa}}\right)$ values [28]. Persistence of SVOCs in indoor environments were investigated by employing ventilation as the removal mechanism [29]. For example, ventilation was found to 
have considerable influence on the levels of airborne polybrominated diphenyl ethers (PBDEs) under constant PBDE emission source strength [30]. Impact of ventilation on indoor SVOCs concentrations were also studied by comparing SVOC prevalence to various filtration conditions in a commercial building [31], where indoor air was re-circulated through filters. A model was developed and applied to describe the effect of ventilation and surface cleaning on indoor residence time of SVOCs, assuming SVOC sources were no longer present [32].

Dust samples, which are relatively easy to obtain, are preferred to be used to study SVOCs in indoor environments. Correlation of SVOCs in indoor dust and indoor air, however, can be influenced by ventilation, as ventilation primarily influences the occurrence and transport of dust, and subsequently the partition of SVOCs in gas and particle phases. Such effects however, have not been well studied for different types of spaces within a building [25]. The objective of the present study was to investigate the presence and behavior of seven OPs in three different types of spaces (offices, conference halls and laboratories) within a single institute building in a university. Some of OPs included in the present study such as TCEP, TCPP and TDCP, are currently undergoing risk assessment by US EPA [33]. Triphenylphosphine oxide (TPPO) was also included as its occurrence in indoor environments has not been investigated so far, despite of limited information indicating their possible presence indoors.

\section{Material and methods}

\subsection{Chemicals}

Seven OPs measured in this study (Table 1) were purchased from Dr. Ehrenstorfer (Augsburg, Germany). Tri-n-butyl-phosphate- $\mathrm{d}_{27}\left(\mathrm{TnBP}_{\mathrm{d}} \mathrm{d}_{27}\right)$ and tri-phenyl-phosphate- $\mathrm{d}_{15}$ (TPhP- $\left.\mathrm{d}_{15}\right)$ were obtained from Cambridge Isotope Laboratories (Andover, USA) and were used as 
surrogates. 2,3,3',4,4',5-hexachlorobiphenyl- $\mathrm{d}_{3}\left(\mathrm{PCB}-156-\mathrm{d}_{3}\right)$ serving as internal standard was obtained from Sigma-Aldrich (Germany). Ethyl acetate, toluene and cyclohexane were HPLC grade from Merck (Darmstadt, Germany).

\section{Table 1}

Abbreviations, CAS numbers and names of target organophosphorus compounds.

\begin{tabular}{cccc}
\hline Abbreviation & CAS no. & Name & $\mathrm{K}_{\text {oa }}$ \\
\hline TCEP & $115-96-8$ & Tri(2-chloroethyl) phosphate & $4.09 \mathrm{E}+07$ \\
TCPP & $13674-84-5$ & Tri(chloropropyl) phosphate & $1.60 \mathrm{E}+08$ \\
TnBP & $126-73-8$ & Tri-n-butyl phosphate & $1.74 \mathrm{E}+08$ \\
TPhP & $115-86-6$ & Triphenyl phosphate & $2.88 \mathrm{E}+08$ \\
TPPO & $791-28-6$ & Triphenylphosphine oxide & $3.14 \mathrm{E}+10$ \\
TDCP & $13674-87-8$ & Tri(dichloropropyl) phosphate & $4.19 \mathrm{E}+10$ \\
TEHP & $78-42-2$ & Tri(2-ethylhexyl) phosphate & $9.62 \mathrm{E}+14$ \\
\hline
\end{tabular}

$\mathrm{K}_{\mathrm{oa}}$ : octanol-air partition coefficient, $\mathrm{K}_{\mathrm{oa}}$ data from EPI Suite 4.1.

\subsection{Sample collection}

Air and dust samples were collected during the period of November 2014 to February 2015. For collecting air samples, the sampler with a particle impactor (HY-100 PM10, Qingdao Hengyuan S.T. Development Co., Ltd.) was set up at a height of $1.25 \mathrm{~m}$ from the floor at the center of each room to collect airborne particles with diameters of $10 \mu \mathrm{m}$ or less $\left(\mathrm{PM}_{10}\right)$. $\mathrm{PM}_{10}$ particles were collected on a fiberglass filter paper (retaining efficient of $99.99 \%$ at $0.3 \mu \mathrm{m}$, Qingdao Hengyuan S.T. Development Co., Ltd) that had been cleaned at $450^{\circ} \mathrm{C}$ for 2 hours. No backup sorbent was used. Indoor air was pumped through a pre-calibrated sampler at a nominal flow rate of $50 \mathrm{l} / \mathrm{min}$ for 24 hours (equal to a nominal air volume of $72 \mathrm{~m}^{3}$ ). Before and after sampling, the filters were covered with aluminum foil, sealed in a metallic container and placed in a refrigerator. Each filter, before and after sampling, was placed in a refrigerator 
( $4{ }^{\circ} \mathrm{C}$ and $40 \%$ relative humidity) overnight to be conditioned for weight measurements. Each filters was weighed three times and the mean value was reported.

In addition to airborne PM samples, ten settled dust areas were sampled by brushing the settled dust from several spots of the same location in order to obtain a sufficient amount of dust for analysis. Dust samples were collected at the same period of time from corresponding spaces where $\mathrm{PM}_{10}$ samples were collected: 5 dust samples from the top upside of the central air-conditioning units (CACU) in offices, 2 dust samples from the lower compartment of the internal air-conditioning unit (IACU) that were placed indoors of the laboratories, and 3 dust samples from cornices of door and window frames in conference halls. All dust samples were sieved through a $100-\mu \mathrm{m}$ mesh device, dust passing through the sieve $(<100 \mu \mathrm{m})$ was collected for analysis.

\subsection{Sample treatment and analysis}

The pre-treatment and purification method for dust samples was the same as that reported by Cristale and Lacorte [34]. The extraction method for OPs from air filters, however, was slightly modified. Briefly, two surrogates $\left(\mathrm{TnBP}^{-\mathrm{d}_{27}}\right.$ and TPhP- $\mathrm{d}_{15}, 100 \mathrm{ng}$ each) were spiked to the filter the night before sample extraction. Each filter was then placed in a 50-ml conical flask to which $10 \mathrm{ml}$ of solvent (ethyl acetate/cyclohexane, 5:2) were added. The sample in the flask was ultra-sonicated for 15 minutes and the solution was collected in a 30 -ml flask. The above extraction procedure was repeated two more times. The extract was dried under nitrogen gas to about $0.5 \mathrm{ml}$ for further cleanup. Solid phase extraction (SPE) cartridges $(1.0 \mathrm{~g}$ / $6 \mathrm{ml}$ Florisil cartridge, Sep-Pak®, Waters, USA) were used for sample clean up. The cartridge 
was conditioned with $6 \mathrm{ml}$ of solvent (ethyl acetate/cyclohexane, 5:2) and the OPs were eluted with $10 \mathrm{ml}$ of solvent (ethyl acetate/cyclohexane, 5:2). The eluate was evaporated under nitrogen to almost dryness and the residue was re-dissolved in $500 \mu l$ ethyl acetate containing 25 ng of internal standard PCB-156- $\mathrm{d}_{3}$ for instrument analysis.

Samples were analyzed using a TSQ Quantum GC-MS/MS (Thermo Scientific, USA) that was equipped with a DB-XLB column $(15 \mathrm{~m} \times 0.25 \mathrm{~mm} \times 0.25 \mu \mathrm{m}$ film thickness, J\&W Scientific, USA). The mass spectrometer was operated in the electron impact (EI) ionization mode. Samples were analyzed in selective reaction monitoring (SRM) mode split up in four time segments. The precursor and product ions selected in the SRM mode for each compound were optimized with suitable collision energy. Detailed information about retention times, quantification and confirmation product ions with their corresponding precursors is provided in Supporting Information (Table S2). Identification of OPs in the samples was performed by comparing their retention time to that of the standards and their product ions in SRM mode to those of the standards.

Inlet, transfer line and ion source temperatures were all set at $280{ }^{\circ} \mathrm{C}$. Analysis was initiated by injecting $1.0 \mu \mathrm{l}$ of extract in splitless mode. The GC oven temperature started at 60 ${ }^{\circ} \mathrm{C}$, immediately increasing to $220^{\circ} \mathrm{C}$ at a rate of $15{ }^{\circ} \mathrm{C} / \mathrm{min}$, then at $20{ }^{\circ} \mathrm{C} / \mathrm{min}$ to the final temperature of $315^{\circ} \mathrm{C}$, which was maintained for $10 \mathrm{~min}$. Helium $(1.5 \mathrm{ml} / \mathrm{min})$ and $\arg$ on $(1.0$ $\mathrm{ml} / \mathrm{min}$ ) was used as a carrier gas and as a collision gas, respectively.

\subsection{Quality assurance/quality control $(Q A / Q C)$ and statistical analysis}

All glassware was soaked overnight in $5 \%(\mathrm{w} / \mathrm{w})$ potassium hydroxide in ethanol, rinsed with 
deionized water and then with acetyl acetate to eliminate possible contamination. Spiked laboratory control samples ( $\mathrm{n}=7$, added at $50 \mathrm{ng} / \mathrm{sample}$ ) showed relative standard deviation (RSD) of $<20.0 \%$ for all OPs (Table S3). Recoveries of OPs were in the range of 87.0-109\% and average recoveries of the surrogates $\left(\mathrm{TnBP}^{-\mathrm{d}_{27}}\right.$ and $\left.\mathrm{TPhP}-\mathrm{d}_{15}\right)$ were $118 \%$ and $83 \%$. Instrument limit of detection (iLOD) was estimated as the lowest amount of a target that can be detected by the instrument. Method detection limit (MDL) was defined as three times the standard deviation of blank samples plus the average value of the blanks (Table S3).

\section{Results and Discussion}

A total of $39 \mathrm{PM}_{10}$ samples, was collected from a teaching building at School of the Environment at Nanjing University, China: nine from offices, 12 from conference halls and 18 from laboratories (Table S4). Summary results of OP levels (mean and standard deviation (S.D.)) in each indoor space are presented in Table 2. In addition to $\mathrm{PM}_{10}$ samples, ten composite dust samples were also analyzed: five from offices, three from conference halls and two from laboratories (Table 3). Information about the environmental conditions of these indoor spaces are given in Table 4.

\section{Table 2}

Levels of airborne OPs $\left(\mathrm{ng} / \mathrm{m}^{3}\right)$ and particles of $\mathrm{PM}_{10}\left(\mu \mathrm{g} / \mathrm{m}^{3}\right)$ in indoor air of offices, conference halls and laboratories in an institute building.

\begin{tabular}{lccccccccc}
\hline & TCEP & TCPP & TDCP & TnBP & TPhP & TEHP & TPPO & $\sum$ OPs & PM $_{10}$ \\
\hline Office- 1 & & & & & & & & & \\
Mean (n=5) & 36 & 10 & 0.34 & 0.53 & 0.40 & 0.30 & 28 & 75 & 104 \\
S.D. & 7.7 & 1.7 & 0.14 & 0.10 & 0.07 & 0.08 & 6.8 & 15 & 37 \\
Office- 2 & & & & & & & & & \\
Mean (n=4) & 23 & 15 & 0.26 & 0.50 & 0.03 & 0.30 & 0.12 & 39 & 160 \\
S.D. & 6.7 & 3.2 & 0.06 & 0.09 & 0.01 & 0.06 & 0.11 & 9.9 & 37 \\
Conference hall-1 & & & & & & & & & \\
Mean (n=7) & 3.7 & 4.3 & 0.99 & 0.26 & 0.29 & 0.79 & 46 & 57 & 154
\end{tabular}


$1.5 \quad 3.0$

0.81

0.08

0.07

0.68

28

29

74

Conference hall-2

Mean $(n=5) \quad 93$

S.D.

$93 \quad 12$

0.79

0.69

0.48

$6.2 \quad 18$

131

116

Laboratory-1

Mean (n=10)

$12 \quad 3.8$

0.13

0.17

0.08

2.8

20

23

54

S.D.

$\begin{array}{ll}5.0 & 8.2 \\ 3.8 & \end{array}$

2.3

0.32

0.27

1.4

1.3

19

135

Laboratory-2

Mean (n=8)

3.8

2.1

1.4

0.15

0.21

1.2

2.5

4.8

50

S.D.

$23 \quad 15$

$0.73 \quad 0.21 \quad 0.09$

$0.10 \quad 0.04$

38

69

5.1

4.9

$\begin{array}{ll}0.20 & 0.03\end{array}$

0.06

0.07

0.04

8.2

35

\section{Table 3}

Concentrations $(\mu \mathrm{g} / \mathrm{g})$ of OPs in dust samples.

\begin{tabular}{lllllllllc}
\hline & & TCEP & TCPP & TDCP & TnBP & TPhP & TEHP & TPPO & $\sum$ OPs \\
\hline Office-1 & DCACU1 & 0.36 & 0.63 & 0.08 & 0.04 & 0.04 & 0.03 & 0.40 & 1.6 \\
Office-1 & DCACU2 & 0.13 & 0.15 & 0.09 & 0.07 & 0.02 & 0.04 & 0.89 & 1.4 \\
\hline Office-2 & DCACU3 & 0.12 & 0.12 & 0.14 & 0.08 & 0.03 & 0.05 & 0.07 & 0.60 \\
Office-2 & DCACU4 & 0.09 & 0.10 & 0.10 & 0.07 & 0.04 & 0.02 & 0.04 & 0.45 \\
Office-2 & DCACU5 & 0.13 & 0.19 & 0.05 & 0.08 & 0.02 & 0.02 & 0.05 & 0.53 \\
\hline Conference hall-1 & DC10 & 0.16 & 0.11 & 0.08 & 0.04 & 0.07 & 0.08 & 0.57 & 1.1 \\
Conference hall-2 & DC6 & 3.0 & 0.51 & 0.13 & 0.12 & 0.19 & 0.25 & 0.89 & 5.1 \\
Conference hall-2 & DC7 & 3.0 & 0.43 & 0.15 & 0.10 & 0.20 & 0.71 & 1.1 & 5.7 \\
\hline Laboratory-1 & DIACU8 & 4.0 & 2.5 & 2.6 & 0.15 & 0.26 & 0.63 & 0.30 & 10 \\
Laboratory-2 & DIACU9 & 42 & 5.7 & 26 & 0.08 & 0.44 & 3.9 & 0.49 & 79 \\
\hline
\end{tabular}

Each dust sample was measured in triplicate and the values in the table are the mean value. For standard deviation of the measurements, see Table S5 in SI.

\section{Table 4}

Description of room settings, space characters and ventilations of different indoor spaces where samples were collected.

\begin{tabular}{|c|c|c|c|c|}
\hline Sites & Room setting & $\begin{array}{l}\text { Floor area } \\
\qquad\left(\mathrm{m}^{2}\right)\end{array}$ & $\begin{array}{c}\text { Building } \\
\text { volume }\left(\mathrm{m}^{3}\right)\end{array}$ & Ventilation $^{\text {a) }}$ \\
\hline $\begin{array}{l}\text { Office-1 (FO1- } \\
\qquad \text { FO5) } \\
\text { (DCAC-1,2) }\end{array}$ & $\begin{array}{c}\text { Densely furnished, Sofa sets, polished furniture, } \\
\text { one computer, printer, and other electronics, } \\
\text { ceramic floor }\end{array}$ & 20 & 74 & Natural \\
\hline $\begin{array}{c}\text { Office-2 } \\
(\mathrm{FO} 23-\mathrm{FO} 26) \\
(\mathrm{DCAC}-3,4,5)\end{array}$ & $\begin{array}{l}\text { Medium furnished, non-foam metallic chairs, } \\
\text { formica-laminated furniture, ten computers, } \\
\text { printer, and other electronics, ceramic floor }\end{array}$ & 20.4 & 75 & Natural \\
\hline $\begin{array}{l}\text { Conference } \\
\text { hall-1 } \\
(\mathrm{FC6}-\mathrm{FC} 12) \\
\text { (DC-10) }\end{array}$ & $\begin{array}{l}\text { Foamy seat painted chairs, multimedia projector, } \\
\text { ceramic flooring, synthetic ceilings, plastic strip } \\
\text { curtains }\end{array}$ & 44.5 & 163 & Closed \\
\hline
\end{tabular}




\begin{tabular}{|c|c|c|c|c|}
\hline $\begin{array}{l}\text { Conference } \\
\text { hall-2 } \\
(\mathrm{FC} 35-\mathrm{FC} 39) \\
(\mathrm{DC}-6,7)\end{array}$ & $\begin{array}{l}\text { Wooden polished furniture, multimedia } \\
\text { projector, recently polished PVC floor, synthetic } \\
\text { ceilings, electronics products like multimedia, } \\
\text { plastic strip curtains }\end{array}$ & 173 & 632 & Closed \\
\hline $\begin{array}{c}\text { Laboratory-1 } \\
\text { (FL13-FL22) } \\
\text { (DIACU-8) }\end{array}$ & $\begin{array}{c}\text { Organic and inorganic chemicals, ceramic floor, } \\
\text { synthetic ceilings, special PVC coated furniture, } \\
\text { 5-refrigerators, large inventory of analytical } \\
\text { instruments }\end{array}$ & 60 & 219 & Forced \\
\hline $\begin{array}{c}\text { Laboratory-2 } \\
\text { (FL27-FL34) } \\
\text { (DIACU-9) }\end{array}$ & $\begin{array}{l}\text { Organic and inorganic chemicals, ceramic floor, } \\
\text { synthetic ceilings, special PVC coated furniture, } \\
\text { 2-refrigerators, Medium inventory of analytical } \\
\text { instruments, New addition of plastic } \\
\text { aquariums/PVC cabinets/tubings for aqua- } \\
\text { toxicity tests }\end{array}$ & 60 & 219 & Forced \\
\hline
\end{tabular}

$\mathrm{PVC}=$ polyvinyl chloride

a: Natural: ventilation largely through open windows; Closed: ventilation largely through mechanical system, window closed; Forced: ventilation largely through forced air withdraw through fume hoods, operated at about $1.8 \mathrm{~m}^{3} / \mathrm{min}$.

In general, among the seven measured OPs, TCEP, TCPP and TPPO were the major compounds found in $\mathrm{PM}_{10}$ samples, though variations in compositions were also observed among various types of spaces. The mean TCEP levels ranged from 3.7 to $93 \mathrm{ng} / \mathrm{m}^{3}$ in indoor air and TCPP showed comparable levels with the mean values ranged from 4.3 to $15 \mathrm{ng} / \mathrm{m}^{3}$ (Table S4). The dominance of TCEP and TCPP in indoor air was reflected in the settled dust samples collected from the corresponding spaces of the building; values in settled dust ranged from 0.09 to $42 \mu \mathrm{g} / \mathrm{g}$ and from 0.10 to $5.7 \mu \mathrm{g} / \mathrm{g}$ for TCEP and TCPP, respectively (Table 3). Levels of the three chlorinated OPs (TCEP, TCPP and TDCP) were in line with reported indoor air values of these chlorinated OPs [1]. Compared to indoor air levels of OPs reported by others, indoor air values of these three chlorinated OPs determined in this study were similar to those reported in China and USA, while levels in Sweden and Japan were higher (Fig. S1). Similar situations applied to settled indoor dust too, where levels of the three chlorinated OPs found in 
this study were similar to levels reported from USA, while Japan and Sweden had higher levels in general (Fig. S2).

Among the four non-halogenated OPs, relatively high TPPO levels in indoor air of both conference halls (46 and $18 \mathrm{ng} / \mathrm{m}^{3}$ ) were found (Table 2). It was interesting to observe that a huge difference of TPPO levels in indoor air existed between Office-1 $\left(28 \mathrm{ng} / \mathrm{m}^{3}\right)$ and Office$2\left(0.12 \mathrm{ng} / \mathrm{m}^{3}\right)$ (Table 2$)$. Unlike the other measured phosphorous compounds, TPPO has a very different structure; it is an organophosphine oxide. This is the first observation of the presence of TPPO in both indoor air and settled indoor dust. The positive identification of this compound was made by comparing the mass spectrum of TPPO from the TPPO standard (Fig. 1b) with the spectrum of TPPO peak from indoor air (Fig. 1c) and indoor dust (Fig. 1d) samples, as well as by their same retention time on the GC separation column. 


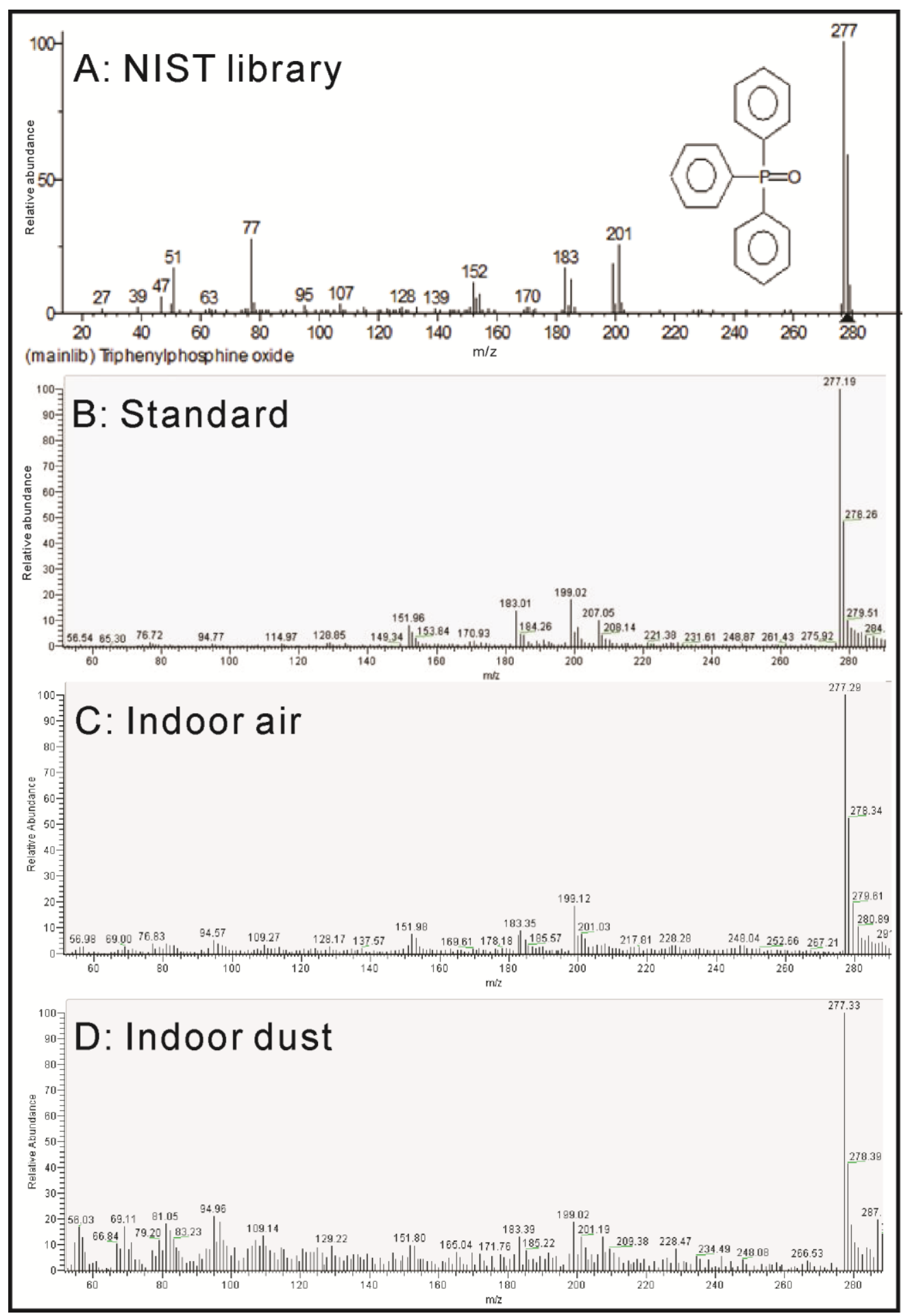

Fig. 1. Mass spectrum of triphenylphosphine oxide (TPPO). A: from NIST MS library, B: from purchased standard, C: from the indoor air $\mathrm{PM}_{10}$ sample, and D: from the settled indoor dust sample.

\subsection{Conference halls}

The sum of OPs levels ( $\left.\sum \mathrm{OPs}\right)$ in the $12 \mathrm{PM}_{10}$ samples from the conference halls ranged from 30.5 to $161 \mathrm{ng} / \mathrm{m}^{3}$ (Fig. 2(a)). There were two distinguished patterns of OP presence among 
these indoor air samples. OPs in samples FC6 to FC12 (conference hall-1) were dominated by TPPO and in samples FC35 to FC39 (conference hall-2) by TCEP. The OP patterns in PM 10 samples were also reflected in the dust samples collected from the conference halls: TPPO dominated OPs in the dust sample (DC10) from conference hall-1, while TCEP dominated OPs in dust samples from conference hall-2 (DC6, DC7) (Fig. 2 (b)). Similar to the indoor air samples, levels of $\sum$ OPs in dust samples from conference hall-1 (DC10) were lower than those of conference hall-2 samples (DC6 and DC7).

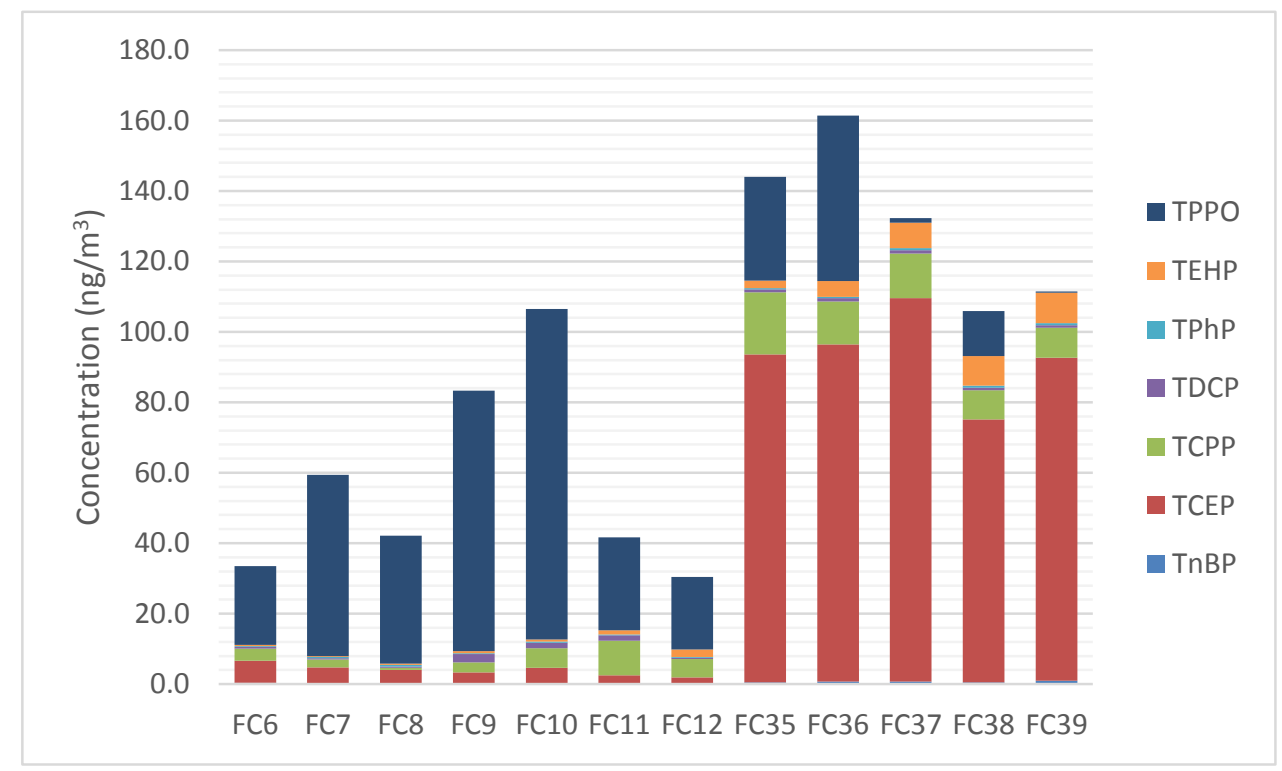

Fig. 2 (a). Levels $\left(\mathrm{ng} / \mathrm{m}^{3}\right)$ of airborne OPs in conference halls (FC6-FC12: Conference hall-1; FC35-FC39: Conference hall-2) 


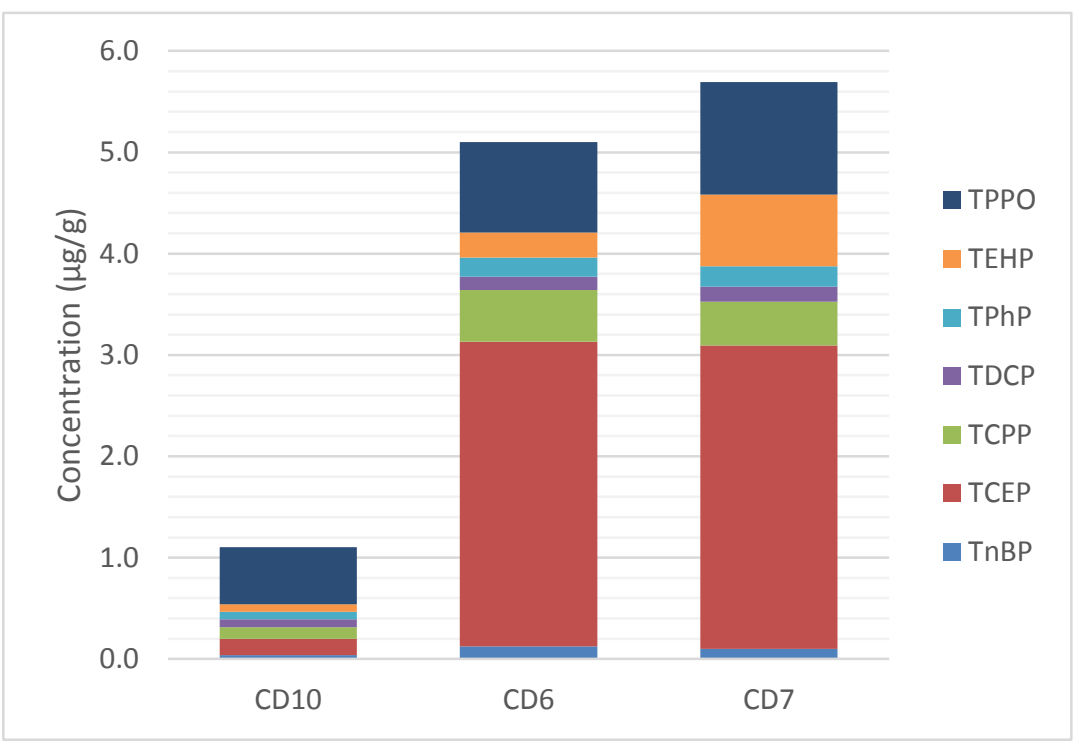

Fig. 2 (b). Levels $(\mu \mathrm{g} / \mathrm{g}$ ) of OPs in the dust of cornice collected from the conference halls (DC10: conference hall1; DC6 and DC7: conference hall-2).

\subsection{Offices}

Levels of $\sum$ OPs in the nine $\mathrm{PM}_{10}$ samples collected from two offices ranged from 27.5 to 100 ng/ $\mathrm{m}^{3}$ (Fig. 3 (a)). Again, different composition patterns of OPs were observed among these samples. While TCEP and TCPP were present at relatively similar levels between the two offices, indoor air samples from Office-1 (FO1 to FO5) had additionally high levels of TPPO (Fig. 3 (a)). These two distinguished composition patterns could also be seen in the dust samples collected in these two offices (Fig. 3 (b)). Dust samples from Office-1 (DCACU1 and DCACU2) had a strong presence of TPPO in addition to TCEP and TCPP. In comparison, only a minute quantity of TPPO was detected in the dust samples from Office-2 (DCACU3, DCACU4 and DCACU5). 


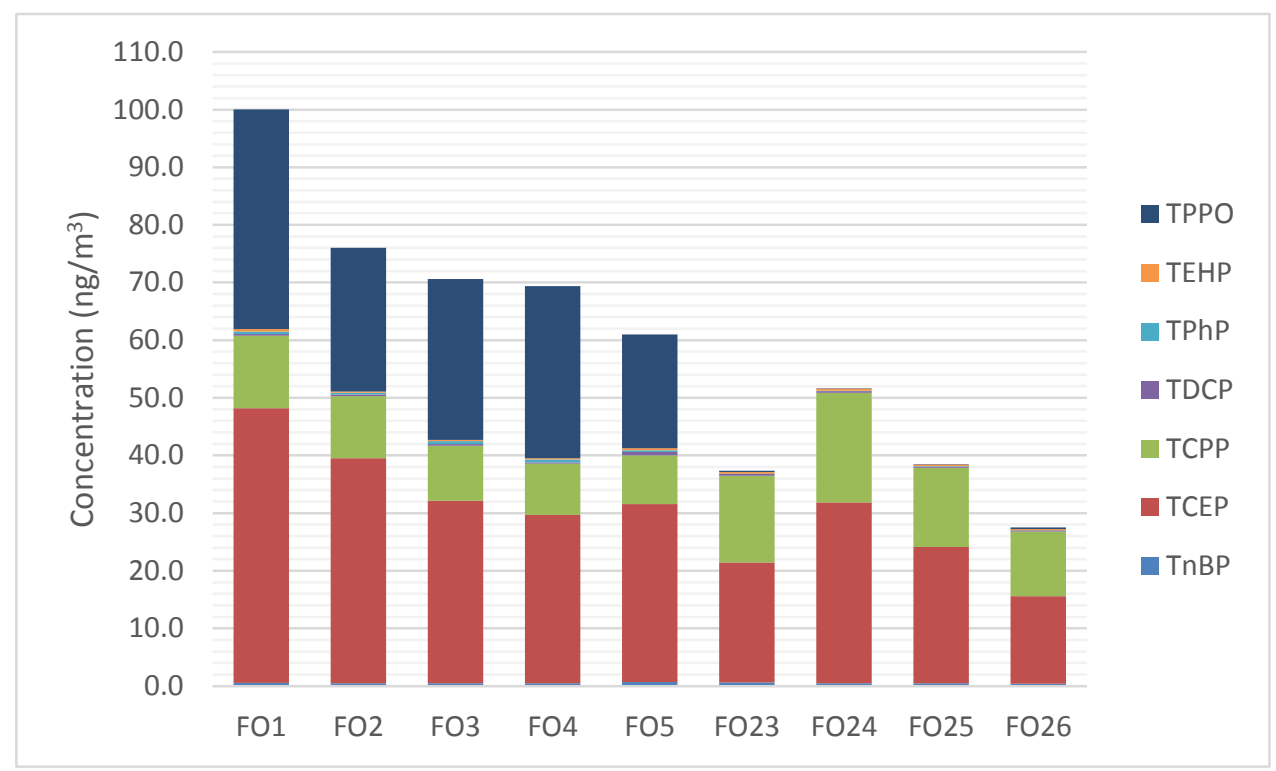

Fig. 3 (a). Levels $\left(\mathrm{ng} / \mathrm{m}^{3}\right)$ of airborne OPs in offices (FO1-FO5: Office-1; FO23-FO26: Office-2)

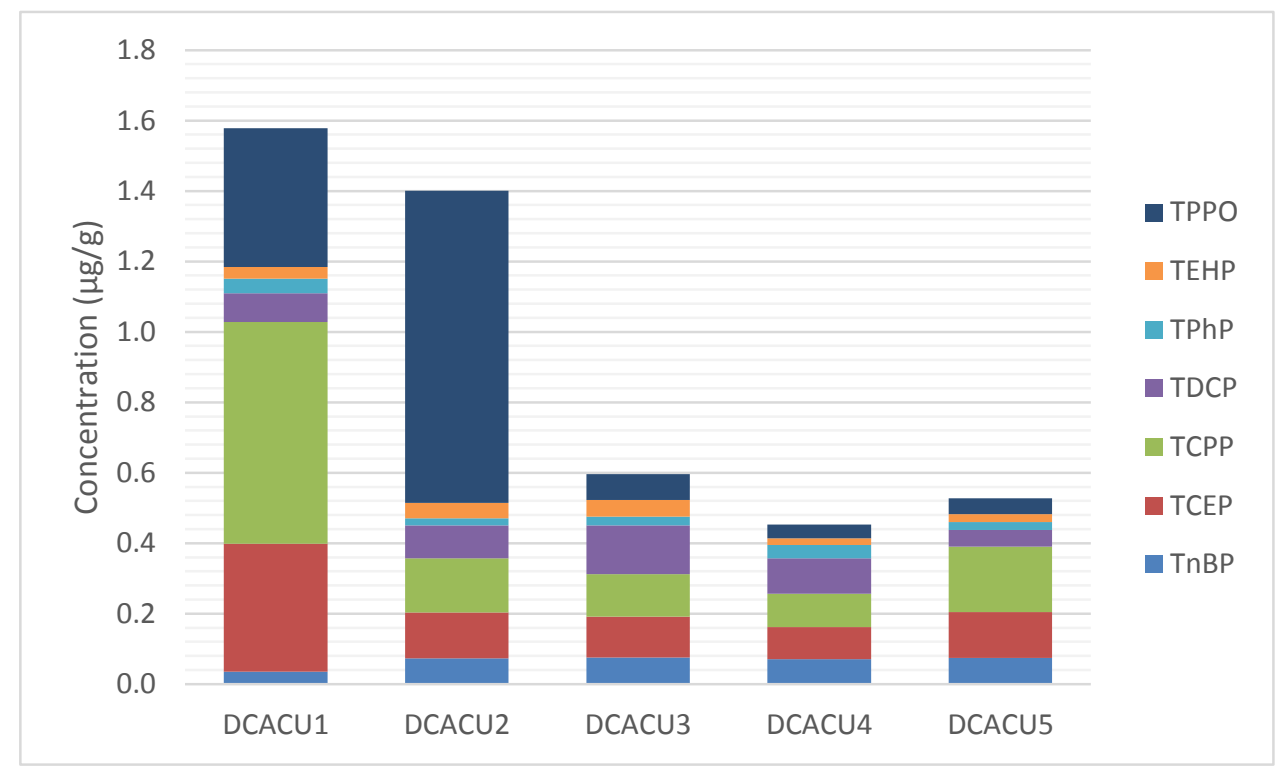

Fig. 3 (b). Levels $(\mu \mathrm{g} / \mathrm{g})$ of OPs in dust of central air-conditioning units (CACU) of the offices (DCACU1 and DCACU2: Office-1; DCACU3-DCACU5: Office-2)

\subsection{Laboratories}

¿OPs among the $18 \mathrm{PM}_{10}$ samples collected from two laboratories ranged from 11.9 to 50.9 $\mathrm{ng} / \mathrm{m}^{3}$. The levels of OPs in the laboratories were relatively low compared to airborne OPs in offices and conference halls. Low OP levels in laboratories might be due to the higher 
ventilation rates in laboratories compared to two other types of indoor spaces. Two dominant OPs in $\mathrm{PM}_{10}$ samples in the laboratories were again TCEP and TCPP, though the ratios of these two OPs varied among the samples. TCEP levels in $\mathrm{PM}_{10}$ samples from laboratory-1 (FL-13 to FL-22) were lower than those from laboratory-2 (FL-27 to FL-34), while the levels of TCPP in $\mathrm{PM}_{10}$ samples were similar between the two laboratories (Fig. 4 (a)). Laboratory-1 also had the noticeable presence of TDCP and TPPO, both were only present in minute quantities in the samples from laboratory-2. The two dust samples, however showed very different levels of OPs although the compositions of the two were very similar, which were dominated by TCEP and TDCP (Fig. 4 (b)).

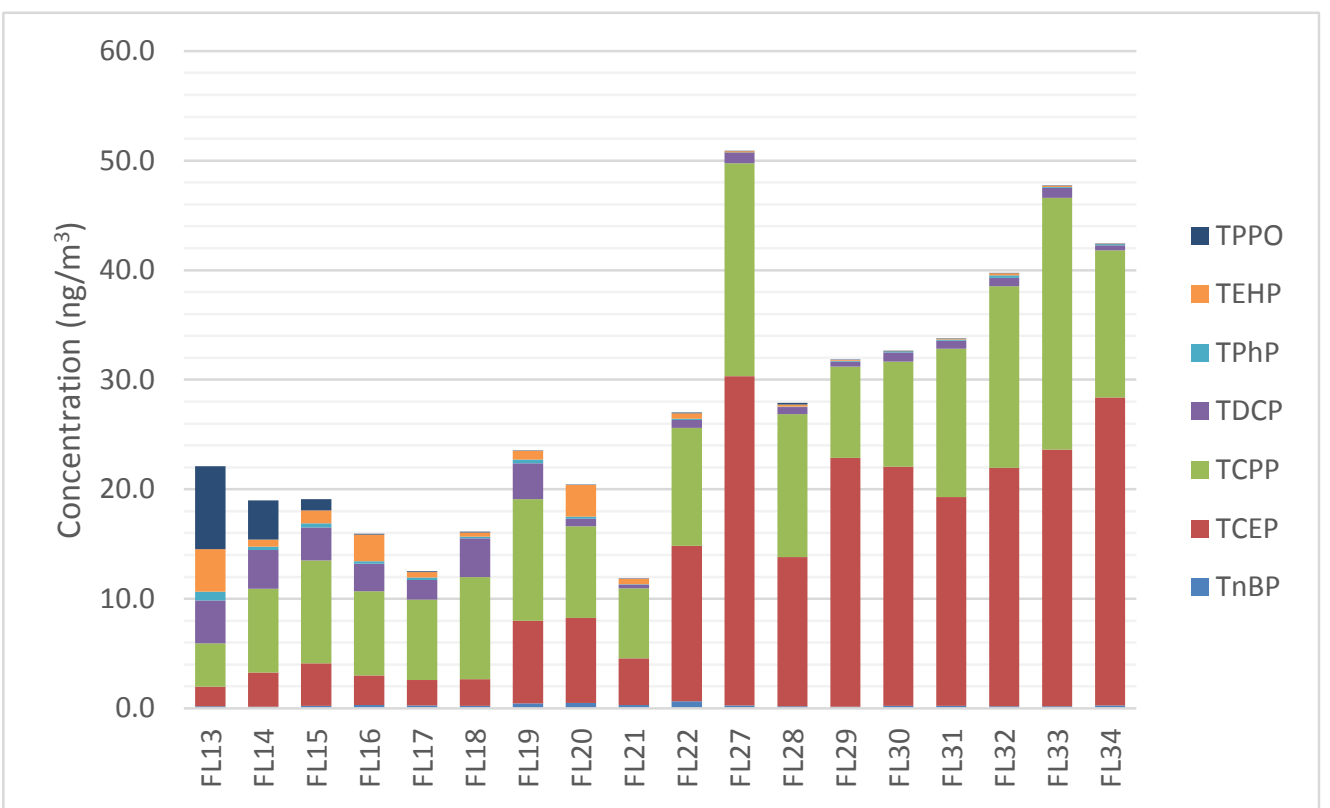

Fig. 4 (a). Levels $\left(\mathrm{ng} / \mathrm{m}^{3}\right)$ of airborne OPs in laboratories (FL13-FL22: Laboratory-1; FL27-FL34: Laboratory-2) 


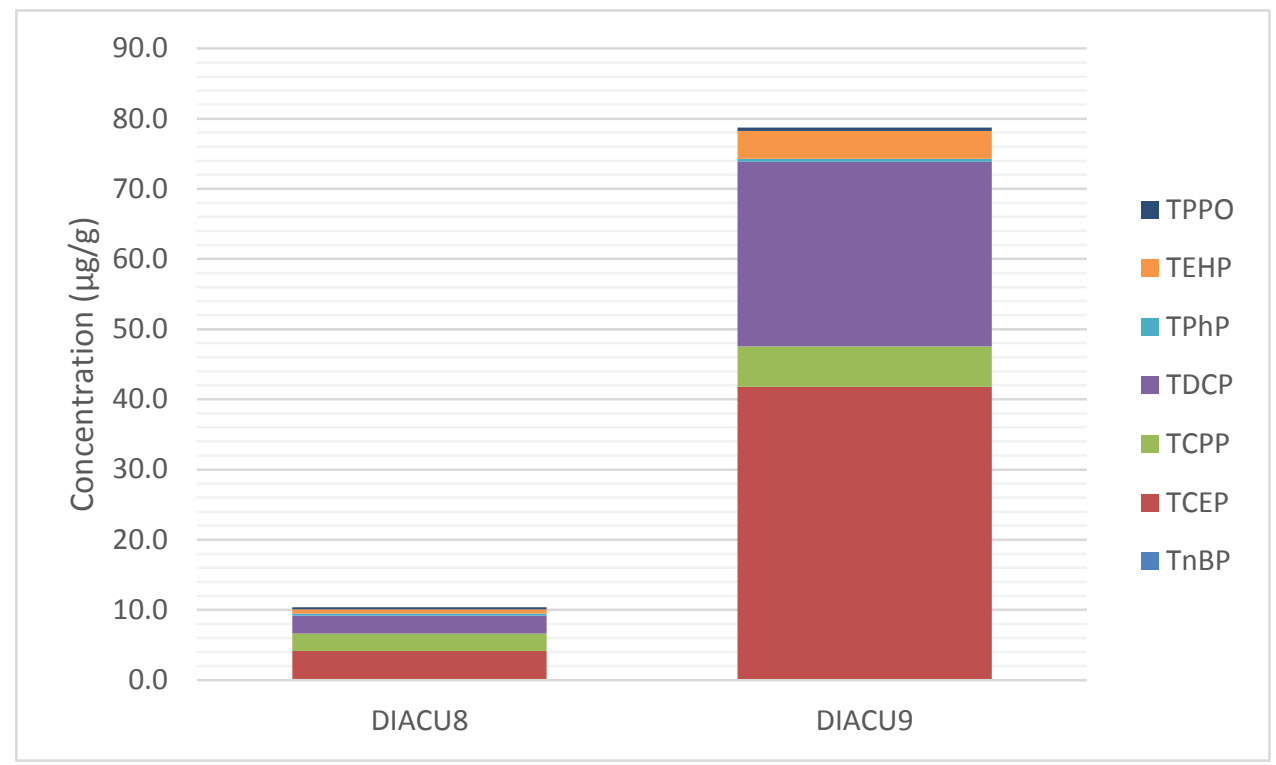

Fig. 4 (b). Levels ( $\mu \mathrm{g} / \mathrm{g}$ ) of OPs in dust of internal air-conditioning units (IACU) of the laboratories (DIACU8: Laboratory-1; DIACU9: Laboratory-2)

\subsection{Prediction of OP Levels in Dust Using Equilibrium Model}

At equilibrium, the relationship of levels of a chemical in gaseous phase $\left(C_{g}\right)$, in airborne particles $\left(\mathrm{C}_{\mathrm{p}}\right)$ and in settled dust $\left(\mathrm{X}_{\text {dust }}\right)$ can be described in Equations (1) to (3), under the assumption that, in addition to equilibrium conditions, the chemical is mainly absorbed in the organic fraction of the dust and octanol is a good substitute for organic matter in the dust and airborne particles for the absorption of chemicals [28].

$$
\begin{aligned}
& \frac{X_{d u s t}}{C_{g}}\left(m^{3} / \mu g\right)=\frac{f_{\text {om_dust }} \times K_{o a}}{\rho_{\text {dust }}\left(\mu g / m^{3}\right)} \\
& C_{g}\left(\mu g / m^{3}\right)=\frac{C_{p}\left(\mu g / m^{3}\right)}{T S P\left(\mu g / m^{3}\right) \times K_{p}\left(m^{3} / \mu g\right)} \\
& C_{g}\left(\mu g / m^{3}\right)=\frac{C g+C_{p}\left(\mu g / m^{3}\right)}{1+T S P\left(\mu g / m^{3}\right) \times K_{p}\left(m^{3} / \mu g\right)} \\
& K_{p}\left(m^{3} / \mu g\right)=\frac{f_{\text {om_part }} \times K_{o a}}{\rho_{\text {part }}\left(\mu g / m^{3}\right)}
\end{aligned}
$$

Where, $f_{\text {om_dust }}$ and $f_{\text {om_part }}$ are the organic matter fraction of the dust and airborne particles, 
respectively. Likewise, $\rho_{\text {dust }}$ and $\rho_{\text {part }}$ are the density of dust and airborne particles, respectively. $\mathrm{K}_{\mathrm{p}}$ is particle-air partition coefficient.

Combing equations 1 to 3 , the levels of OPs in settled dust can be predicted by measured concentrations in airborne particulate matters $\left(\mathrm{C}_{\mathrm{p}}\right)$ and levels of total suspended particulate (TSP) in the air (Equation 4). In this study, $\mathrm{PM}_{10}$ particles in indoor air were collected and measured to represent TSP.

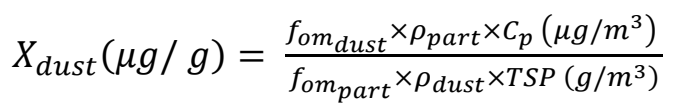

According to equation 4, there is a relationship between the concentrations of SVOCs in airborne particles and settled dust at equilibrium. Since $\mathrm{C}_{\mathrm{p}}$ and TSP were experimentally determined, concentrations of OPs in settled dust can be predicted by the properties (fraction of organic matter, $f_{o m}$ and density, $\rho$ ) of airborne particles and settled dust. Notice that in equation 4 , the concentration unit of TSP is $\mathrm{g} / \mathrm{m}^{3}$.

Based on information available in the literature, Weschler and Nazaroff [28] used the following values, $\mathrm{f}_{\text {om_part }}=0.4, \rho_{\text {part }}=1 \mathrm{E} 9 \mathrm{mg} / \mathrm{m}^{3}, \mathrm{f}_{\text {om_dust }}=0.2$ and $\rho_{\text {dust }}=2 \mathrm{E} 9 \mathrm{mg} / \mathrm{m}^{3}, \mathrm{TSP}=$ $20 \mu \mathrm{g} / \mathrm{m}^{3}$, to calculate concentration of a variety of SVOCs in settled dust. Same $f_{o m}$ and $\rho$ values were used in the present study. TSP value in equation 4 however was replaced by the measured $\mathrm{PM}_{10}$ concentration $\left(\mathrm{g} / \mathrm{m}^{3}\right)$ in the present study. Measured airborne OP levels were used to replace $C_{p}$ value in equation 4 . Scatter plot of predicted and measured OP levels in dust in each type of indoor spaces was presented in Fig. 5, which showed that there were reasonably well correlations in each of the three types of indoor spaces, with coefficient of determination $\left(\mathrm{r}^{2}\right)$ values of $0.633,0.698$ and 0.474 for cornice dust (conference halls), CACU dust (offices) 
and IACU dust (laboratories), respectively.

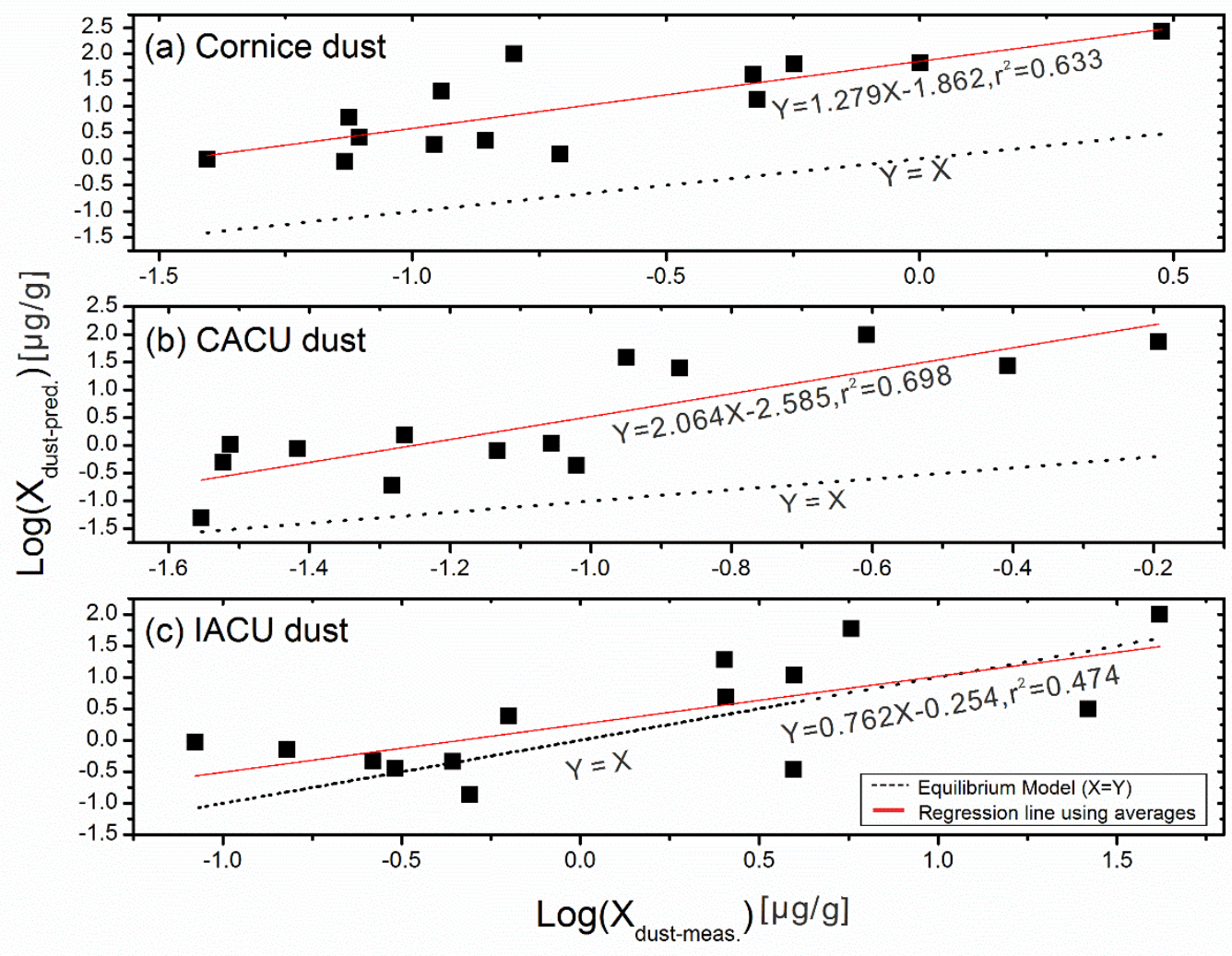

Fig. 5. Scatter plot of measured ( $\left.X_{\text {dust-meas. }}\right)$ versus predicted $\left(X_{\text {dust-pred. }}\right)$ OP levels in (a) cornice dust from conference halls, (b) CACU dust from offices and (c) IACU dust from laboratories. All correlations are statistically significant $(\mathrm{P}<0.01)$.

Different correlation patterns can be observed in Fig. 5. In offices (Fig. 5a) and conference halls (Fig. 5b), where the dust samples were collected from the surface of the cornice and top of ventilation duct, the measured OP levels in the dust were one to two orders of magnitude lower than the predicted values. The difference between predicted and measured OP levels was less influenced by the levels of OPs in conference halls (slope $=1.2$ ) than in offices (slope $=2.1)$. Despite of the fact that the data in Fig. $5 \mathrm{c}$ were more scattered, the predicted and measured OP levels in the dust samples that were collected from inside the lower chamber of 
the ventilation unit from laboratories seemed to have matched quite well. Dusts accumulated inside the ventilation duct represent the dust that incorporated fluctuations of both spatial and non-spatial concentration.

Among the seven OPs measured in this study, four have $\mathrm{K}_{\mathrm{oa}}$ values in the range of $10^{7}-10^{8}$, while the other three have $\mathrm{K}_{\mathrm{oa}}$ values $>10^{10}$. Further regression analysis of predicted and measured OPs levels in dust samples base on $\mathrm{K}_{\mathrm{oa}}$ values showed that the regression results were quite similar between these two groups of OPs, only difference observed for the IACU dust was likely due the scattered data of OPs with $K_{o a}>10^{10}$ as demonstrated by low $r^{2}$ value of 0.2599 as shown in Fig. S3.

The difference between predicted and measured OP concentrations in dust observed in this study (data marked by $\mathbf{\square}, \bullet$ and $\mathbf{\Delta}$ ) falls into the general trends of other SVOCs (data marked by +) reconstructed from Weschler and Nazaroff [28], in which predicted levels were lower than those measured in indoor dust samples (Fig. 6). In some cases, the difference could be as large as two to three orders of magnitude. Systematic over-prediction of SVOC concentrations in settled dust based on SVOC concentrations in $C_{p}$ and/or in $C_{g}$ cannot be explained solely by the large variations in the $f_{\text {om }}$ and $\rho$ values of airborne particles and settled dust indoors that were reported from in various studies [35-37].

The consistent over-prediction of SVOC concentrations in dust is likely attributed to the fact that in most indoor environments, SVOCs levels in indoor air are at most in a steady state if there is a constant emission and a constant air exchange rate of the indoor space. Given the low concentration of SVOCs in indoor air and periodical removal of settled dust indoors through cleaning, it is unlikely that an equilibrium in concentration between airborne particles 
or gaseous phase and settled dust could be reached [38]. In the present study, $\mathrm{C}_{\mathrm{p}}$ values were derived from OP values determined in the filters. Since filters may not only trap airborne particles but also act as a possible adsorbent medium for SVOCs. The determined mass of OPs may include some gaseous phase OPs. Although there is no empirical data to quantify the gaseous phase mass being trapped in the filter, possible inclusion of some mass from gaseous phase in $C_{p}$ value could further aggregate the differences between predicted and measured concentrations in settled dust.

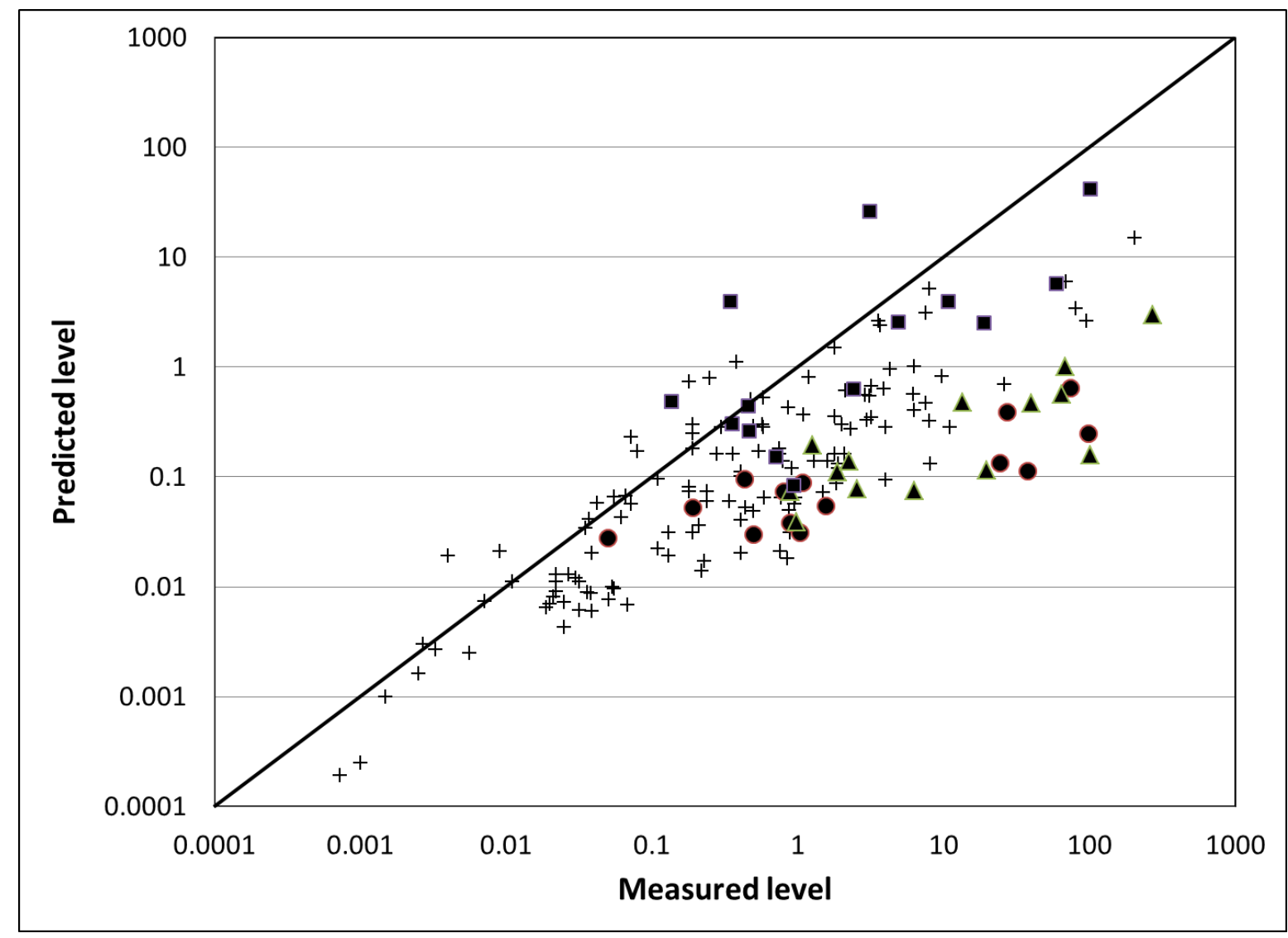

Fig. 6. Comparison of model predicted (x-axis) and measured (y-axis) SVOC concentration $(\mu \mathrm{g} / \mathrm{g})$ in indoor settled dust. Markers: $\mathbf{\square}$ : dust from laboratories; $\bullet$ : dust from offices; and $\boldsymbol{\Delta}$ : conference halls in the present study; the rest data (+) are from reference [28].

The dust samples in this study were collected from cornice and air conditioning units; such places, unlike furniture surfaces and floors, are not subject to normal house cleaning. They therefore would stay in the indoor environment for longer time and may tend to be closer 
to the equilibrium concentration. Although they are useful in the application of prediction model discussed in the paper, situations might be different when predicting human contacts to dusts in areas that are more frequently being cleaned.

\section{Conclusion}

The present study measured seven OPs in airborne particles and settled dust samples collected from three different types of indoor spaces (offices, conference halls and laboratories) in an institute building in Nanjing University. TCEP, TCPP and TPPO were the three major congeners of OPs found indoors. The results showed that use of certain products indoors such as cushion chairs and sofa, vinyl floors furnished with floor polish and computer/electronic equipment contributes to the presence of OPs. This is the first report of the presence of TPPO in indoor environments with relatively high levels of TPPO. The finding indicated possible use of TPPO in indoor products, although the actual sources cannot be identified.

Good correlation between measured and model predicted OP concentration in settled dust was demonstrated; however model-predicted values were consistently higher. The correlation demonstrated that OPs in airborne particles and in settled dust can be predicted from one for the other, although further research is needed to explain the difference in the absolute values between measurements and predictions for typical indoor environments and to develop an empirical coefficient to correct the predicted values.

An important advantage of indoor dust sampling is that settled dust had been accumulating for a long duration of time and thus the levels of OPs found in the dusts could reflect long-term exposure. Dust samples are also widely available and relatively easy to collect. 
Further study on the correlation of SVOC concentrations between dust and airborne particles can lead to more effective use of dust data to study human exposure, including inhalation exposure to SVOCs such as OPs in indoor environments.

\section{Acknowledgments}

This research was supported financially through funds from National Science Foundation of China (21207061), Ministry of Education of China (20120091120017), Chinese Government Scholarship, Environment Monitoring Fund (1303) of Jiangsu Province, and Canadian government Clean Air Regulatory Agenda. 


\section{References:}

[1] Wei G-L, Li D-Q, Zhuo M-N, Liao Y-S, Xie Z-Y, Guo T-L, et al. Organophosphorus flame retardants and plasticizers: Sources, occurrence, toxicity and human exposure. Environmental Pollution. 2015;196:29-46.

[2] van der Veen I, de Boer J. Phosphorus flame retardants: Properties, production, environmental occurrence, toxicity and analysis. Chemosphere. 2012;88:1119-53.

[3] Ceresana. Market Study: Flame Retardants. 3rd ed. February 20142015. p. 380.

[4] Marklund A, Andersson B, Haglund P. Organophosphorus flame retardants and plasticizers in air from various indoor environments. Journal of Environmental Monitoring. 2005;7:814-9.

[5] Hartmann PC, Bürgi D, Giger W. Organophosphate flame retardants and plasticizers in indoor air. Chemosphere. 2004;57:781-7.

[6] Melgarejo M, Mendiola J, Koch HM, Moñino-García M, Noguera-Velasco JA, Torres-Cantero AM. Associations between urinary organophosphate pesticide metabolite levels and reproductive parameters in men from an infertility clinic. Environmental Research. 2015;137:292-8.

[7] Salamova A, Ma Y, Venier M, Hites RA. High Levels of Organophosphate Flame Retardants in the Great Lakes Atmosphere. Environmental Science \& Technology Letters. 2014;1:8-14.

[8] Yang F, Ding J, Huang W, Xie W, Liu W. Particle Size-Specific Distributions and Preliminary Exposure Assessments of Organophosphate Flame Retardants in Office Air Particulate Matter. Environmental Science \& Technology. 2014;48:63-70.

[9] Rodil R, Quintana JB, Concha-Graña E, López-Mahía P, Muniategui-Lorenzo S, Prada-Rodríguez D. Emerging pollutants in sewage, surface and drinking water in Galicia (NW Spain). Chemosphere. 2012;86:1040-9.

[10] Wang R, Tang J, Xie Z, Mi W, Chen Y, Wolschke H, et al. Occurrence and spatial distribution of organophosphate ester flame retardants and plasticizers in 40 rivers draining into the Bohai Sea, north China. Environmental Pollution. 2015;198:172-8.

[11] Bollmann UE, Möller A, Xie Z, Ebinghaus R, Einax JW. Occurrence and fate of organophosphorus flame retardants and plasticizers in coastal and marine surface waters. Water Research. 2012;46:531-8.

[12] Rakotomalala M, Wagner S, Döring M. Recent Developments in Halogen Free Flame Retardants for Epoxy Resins for Electrical and Electronic Applications. Materials. 2010;3:4300.

[13] Hu F-H, Wang L-S, Cai S-F. Solubilities of Triphenylphosphine Oxide in Selected Solvents. Journal of Chemical \& Engineering Data. 2009;54:1382-4.

[14] Dodson RE, Camann DE, Morello-Frosch R, Brody JG, Rudel RA. Semivolatile Organic Compounds in Homes: Strategies for Efficient and Systematic Exposure Measurement Based on Empirical and Theoretical Factors. Environmental Science \& Technology. 2015;49:113-22.

[15] Jaakkola JJK, Knight TL. The Role of Exposure to Phthalates from Polyvinyl Chloride Products in the Development of Asthma and Allergies: A Systematic Review and Meta-analysis. Environmental Health Perspectives. 2008;116:845-53.

[16] Liang Y, Xu Y. The influence of surface sorption and air flow rate on phthalate emissions from vinyl flooring: Measurement and modeling. Atmospheric Environment. 2015;103:147-55.

[17] Shi S, Zhao B. Estimating indoor semi-volatile organic compounds (SVOCs) associated with settled dust by an integrated kinetic model accounting for aerosol dynamics. Atmospheric Environment. 2015;107:52-61.

[18] Wu Y, Cox SS, Xu Y, Liang Y, Won D, Liu X, et al. A reference method for measuring emissions of SVOCs in small chambers. Building and Environment. 2016;95:126-32.

[19] Xiong J, Cao J, Zhang Y. Early stage C-history method: Rapid and accurate determination of the key SVOC emission or sorption parameters of indoor materials. Building and Environment. 2016;95:314-21. 
[20] Liu C, Zhang Y. Characterizing the equilibrium relationship between DEHP in PVC flooring and air using a closed-chamber SPME method. Building and Environment. 2016;95:283-90.

[21] Mao Y-F, Li Z, He Y-L, Tao W-Q. CFD analysis of SVOC mass transfer in different chambers. International Journal of Heat and Mass Transfer. 2016;99:613-21.

[22] XU Y, Little JC. Predicting Emissions of SVOCs from Polymeric Materials and Their Interaction with Airborne Particles. Environmental Science \& Technology. 2006;40:456-61.

[23] Liu Z, Ye W, Little JC. Predicting emissions of volatile and semivolatile organic compounds from building materials: A review. Building and Environment. 2013;64:7-25.

[24] Chen C, Zhao B. Review of relationship between indoor and outdoor particles: I/O ratio, infiltration factor and penetration factor. Atmospheric Environment. 2011;45:275-88.

[25] Liu C, Zhang Y, Benning JL, Little JC. The effect of ventilation on indoor exposure to semivolatile organic compounds. Indoor Air. 2015;25:285-96.

[26] Shi S, Zhao B. Modeled Exposure Assessment via Inhalation and Dermal Pathways to Airborne Semivolatile Organic Compounds (SVOCs) in Residences. Environmental Science \& Technology. 2014;48:5691-9.

[27] Liu C, Zhao B, Zhang Y. The influence of aerosol dynamics on indoor exposure to airborne DEHP. Atmospheric Environment. 2010;44:1952-9.

[28] Weschler CJ, Nazaroff WW. SVOC partitioning between the gas phase and settled dust indoors. Atmospheric Environment. 2010;44:3609-20.

[29] Weschler CJ, Nazaroff WW. Semivolatile organic compounds in indoor environments. Atmospheric Environment. 2008;42:9018-40.

[30] Zhang X, Diamond ML, Ibarra C, Harrad S. Multimedia Modeling of Polybrominated Diphenyl Ether Emissions and Fate Indoors. Environmental Science \& Technology. 2009;43:2845-50.

[31] Parthasarathy S. Modeling indoor exposures to VOCs and SVOCs as ventilation rates vary. 10th International Conference of Healthy Building. Brisbane, Australia2012.

[32] Shin H-M, McKone TE, Tulve NS, Clifton MS, Bennett DH. Indoor Residence Times of Semivolatile Organic Compounds: Model Estimation and Field Evaluation. Environmental Science \& Technology. 2013;47:859-67.

[33] U.S.E.P.A. TSCA Work Plan Chemical Problem Formulation and Initial Assessment Cyclic Aliphatic Bromides Cluster Flame Retardants. Assessing and Managing Chemicals under TSCA. United States: Office of Chemical Safety and Pollution Prevention; 2016.

[34] Cristale J, Lacorte S. Development and validation of a multiresidue method for the analysis of polybrominated diphenyl ethers, new brominated and organophosphorus flame retardants in sediment, sludge and dust. Journal of chromatography A. 2013;1305:267-75.

[35] Hunt A, Johnson DL, Watt JM, Thornton I. Characterizing the sources of particulate lead in house dust by automated scanning electron microscopy. Environmental Science \& Technology. 1992;26:1513-23.

[36] Fromme H, Lahrz T, Hainsch A, Oddoy A, Piloty M, Ruden H. Elemental carbon and respirable particulate matter in the indoor air of apartments and nursery schools and ambient air in Berlin (Germany). Indoor Air. 2005;15:335-41.

[37] Turpin BJ, Lim H-J. Species Contributions to PM2.5 Mass Concentrations: Revisiting Common Assumptions for Estimating Organic Mass. Aerosol Science and Technology. 2001;35:602-10.

[38] Little JC, Weschler CJ, Nazaroff WW, Liu Z, Cohen Hubal EA. Rapid Methods to Estimate Potential Exposure to Semivolatile Organic Compounds in the Indoor Environment. Environmental Science \& Technology.

2012;46:11171-8. 


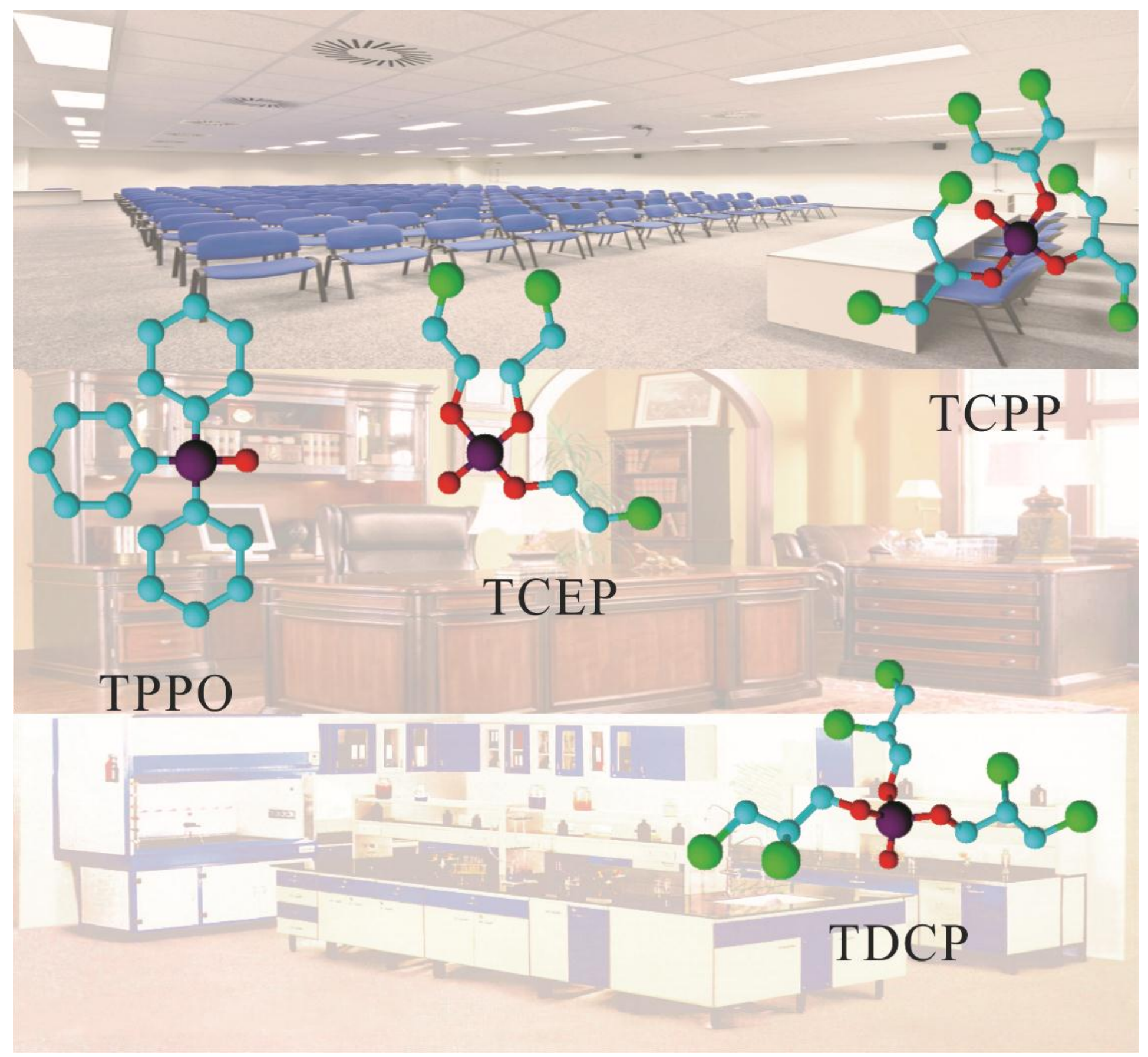

